\title{
Effect of Physical Parameters on Green Synthesis of Gold Nanoparticles using Zea Mays Extract
}

\author{
Ravi Jon, Neha Martin, Prabhakara Rao Dasari, Ajit Paul, Vipul Singh
}

\begin{abstract}
Gold nanoparticles (AuNPs) were produced by green synthesis method by utilization of Zea Mays Extract as the reducing and stabilizing solution. Selected parameters like Time, Temperature, pH, Light and Concentration effects on the preparation of gold nanoparticles was analyzed by $\mathrm{UV}$-Visible Spectroscopy (UV-Vis.). The size was measured through Dynamic Light Scattering (DLS) and also confirmed by Transmission electron microscopy (TEM) techniques, it is also observed that all the reaction time, Temperature, Concentration and reaction time are very essential parameters which should be noticed with high precession during the synthesis of Gold nanoparticles.
\end{abstract}

Keywords: Green synthesis, Gold nanoparticles, physical parameters effect.

\section{INTRODUCTION}

Nowadays, nanoparticles (NPs) have drawn glorious thought in view of their significant properties on different fields, for example, restorative, sensor, optical, electronic, furthermore, Biomedical application [1].The size of nanoparticles depends upon many parameters but the reducing agent and the $\mathrm{pH}$ of the solution are main important parameters [2]. Gold nanoparticles were prepared in fluorescent light [3] and at different reaction temperature [4]. Some Microorganisms were used for the synthesis and nucleation, of the metal nanomaterials. Many microorganisms are used in intracellular or extracellular synthesis process of metal nanoparticles. Cell filtrate is very important to control the polydispersity and size of the nanoparticles in extracellular synthesis. The cell filtrate in synthesis method is more efficient then intercellular synthesis techniques [5]. The gold nanoparticles were synthesized through various extract like endemic plants [6], plants mediated, Ginkgo Biloba leaf extract, Pistacia

Revised Manuscript Received on December 30, 2019.

* Correspondence Author

Ravi Jon*, Department of Physics, FOS, SHUATS, Prayagraj- INDIA. Email: ravi.john@shiats.edu.in

Neha Martin, Christian College of Nursing, SHUATS, PrayagrajINDIA Email: nhmartin0@gmail.com

Prabhakara Rao Dasari , Department of Chemistry, FOS, SHUATS, Prayagraj- INDIA. Email: Prabhakara.rao@shiats.edu.in

Ajit Paul, Department of Mathematics, FOS, SHUATS, PrayagrajINDIA.Email: Ajit.paul@shiats.edu.in

Vipul Singh, Department of Physics, FOS, SHUATS, Prayagraj- INDIA. Email: Vipul.singh@shiats.edu.in

(C) The Authors. Published by Blue Eyes Intelligence Engineering and Sciences Publication (BEIESP). This is an open access article under the CC BY-NC-ND license (http://creativecommons.org/licenses/by-nc-nd/4.0/)
Atlantica. Recently, it was reported that selected pathogenic bacteria's resistance has been increased against the synthetic drugs. The seeds and fruits which contain the Carbohydrates can be used as stabilizer and also a reducing agent, leading to the formation of noble metal nanoparticles. it was also observed that water soluble nanoparticles showed great antimicrobial applications .

The main purpose of this research is to prepare costeffective, small size and eco-friendly gold nanoparticles by using Zea Mays extract as reducing and stabilizing agent and also the effect of physical parameters on the green synthesis of AuNPs were investigated.

\section{MATERIALS AND METHODOLOGY}

\section{A. Preparation of extract}

The detailed study on the green synthesis of gold nanoparticles was carried out from Zea Mays extract; Zea Mays was purchased from local market Allahabad, and Gold(III) chloride or Chloroauric acid(HAuCl4) was purchased from [Sigma-Aldrich, USA: 99.99\%], deionized water was purchased by Scientific India. Mature Zea Mays granules were dried in direct sunlight then washed thoroughly with deionized water. The Zea Mays granules were ground into a fine powder then $100 \mathrm{gm}$ fine powder was mixed with 500ML deionized water and boiled for 50 minutes at $60^{\circ} \mathrm{C}$ and then centrifuged at $5000 \mathrm{rpm}$ for 15 minutes and separated through filter paper (Whatman no. 1). The Zea Mays extract solution was used after 1 hour of preparation. The separated solution was used as reducing and stabilizing agents for the further research work.

\section{B. Green synthesis of AuNPs}

For the preparation of the green gold nanoparticles, $10 \mathrm{ml}$ of Zea Mays extract solution was add to the $100 \mathrm{ML}$ of $1 \mathrm{mM}$ Gold Chloride solution. The mixture was stirred at $60^{\circ} \mathrm{C}$ and $500 \mathrm{rpm}$ by using magnetic stirrer. The colour changes from yellow to red ensure the formation of green gold nanoparticles. The reduction of green synthesized gold nanoparticles was investigated by analyzing samples taken from solutions at fixed time period, $\mathrm{pH}$, Temperature, Light conditions, Concentration and analyzing through UV- Vis. Spectroscopy. The maximum wavelength and absorbance were recorded for each sample through UV-Vis spectra [10].

\section{Characterization of Green Gold nanoparticles}

Ultraviolet visible spectrometer (Systronics double beam spectrophotometer 2202, India) was used to identify the absorption intensity in the range of 300-700 nm. 
(TEM- JEM-2100, JEOL, Japan) was used to observe microstructures of green AuNPs and DLS. FTIR (Perkin Elmer Spectrum 2, Germany) was used to identify the functional groups present in the suspension.

\section{RESULTS AND DISCUSSION}

Fig. 1 showed the UV-Visible spectra of the green gold nanoparticles which were confirmed through the colour change from light yellow to ruby red colour.

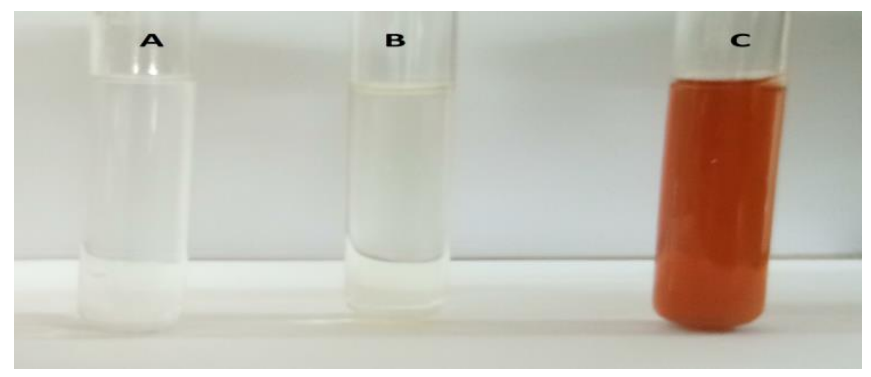

Fig.1 Visual observation of Gold nanoparticles (AuNPs), $\begin{array}{ll}\text { (A) Zea Mays Extract } & \text { (B) Chloroauric acid (C) Gold }\end{array}$ nanoparticles (AuNPs).

\section{A. Time Effect}

Fig. 2 showed that no reduction was noticed in the first 10 min (SPR) peak was observed $540 \mathrm{~nm}$ after $15 \mathrm{~min}$ of reaction, And almost constant after 90 min up to $720 \mathrm{~min}$, which confirmed the completion of reaction. The colour change is the clear indication of formation of AuNPs when $1 \mathrm{mM} \mathrm{HauCl} \mathrm{H}_{4}$ was mixed to Maize extract at different time slots. The surface plasmon resonance peak of solution was noticed that the intensity of the colour change is proportional to the reaction time of the solution as the reaction time increased the absorbance also increased. In the beginning there was no change in colour but it starts instantly after 10 minutes of the reaction till $12 \mathrm{hrs}$ of reaction time.

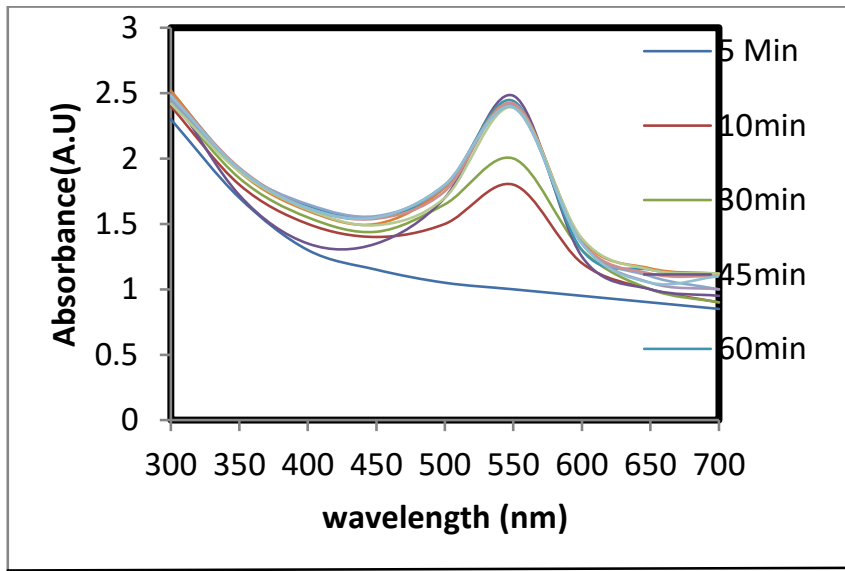

Fig. 2- UV-Visible spectra if AuNps synthesized by Zea Mays (Maize) extract after the different time reaction.

\section{B. Concentration Effect}

Fig.3 showed the Concentration-effect the synthesis of AuNPs, different samples of the concentration of Chloroauric acid $(0.5 \mathrm{mM}, 1 \mathrm{mM}, 2 \mathrm{mM}$ and $5 \mathrm{mM})$ were prepared and analyzed through UV-Vis and max absorbance peak was observed at the $1 \mathrm{mM}$ solution. The synthesis of the AuNPs increase as the concentration of the
Tetrachloroauric acid increased. The surface plasmon resonance peak and its sharpness increased at high concentration and showed the increased in the Gold nanoparticles size and the absorbance peak was higher at normal concentration. The production of green AuNPs was little slower at low concentration and high at high concentration .

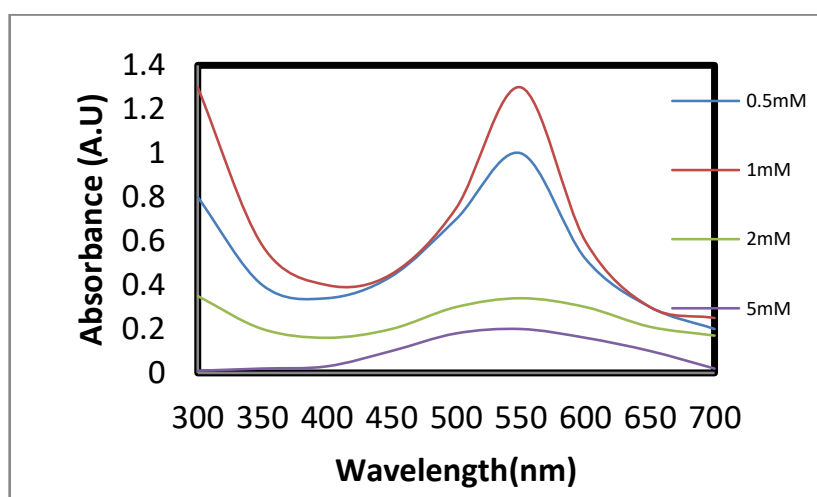

Fig.3 UV-Visible spectra if AuNPs synthesized by Zea Mays (Maize) extract at different Concentration of Chloroauric acid ( $\left.\mathrm{HAuCl}_{4}\right)$.

\section{Effect of pH}

$\mathrm{pH}$ play an significant character in the synthesis of NPs showed in Fig. 4. In this study, the $\mathrm{pH}$ influence the green synthesis of gold nanoparticles was studied in the range from 3 to 11. For the analysis of synthesis of gold nanoparticles visual observations and UV-Vis was used for the effect of $\mathrm{pH}$, It was observed that at $\mathrm{pH}=6$ to 7 the colour starts changes from yellow to red colour; $\mathrm{pH}$ controlled the shape, size and stability of AuNPs.. Initially at $\mathrm{pH}=3,4$ and 5 the synthesis of the AuNPs was very slow and as the ph was further increased and it reaches at $\mathrm{pH}=6$ to 7 the reaction was very high but as the $\mathrm{pH}$ increased further the absorbance value decreased as $\mathrm{pH}$ increased.

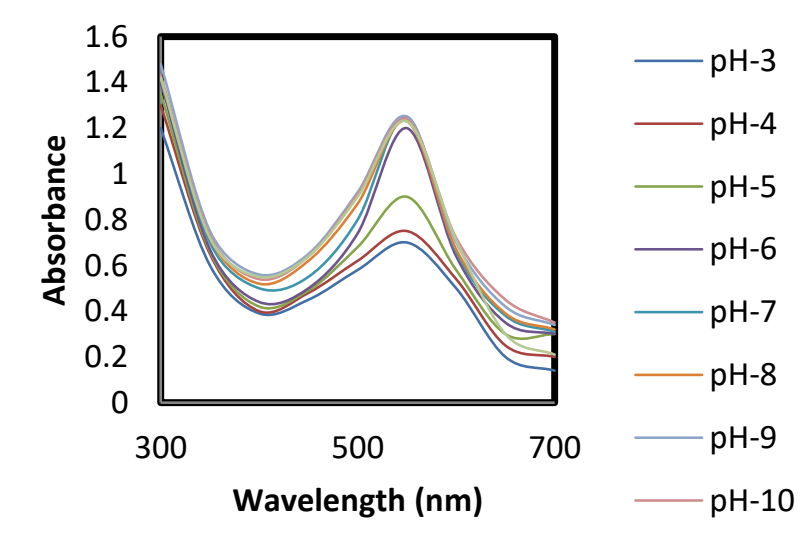

Fig.4 UV-Visible spectra if AuNPs synthesized by Zea Mays (Maize) extract at different pH levels.

\section{Effect of Light}

AuNPs were prepared in different light conditions and it was observed by visual observations and through UV-Vis spectrometer the process of AuNPs in sunlight was rapid in comparison to normal light, UV light, Tube light, Moon light and in dark room. 
AuNPs were prepared in various light conditions to see the effect on biosynthesis on gold nanoparticles such as Dark, UV lights, Moonlight, Control and Sunlight.

It was observed in Fig.5 that the synthesis process of gold nanoparticles was rapid under the sunlight. The sample did not showed any colour change in dark throughout the night. The reaction sample showed small absorbance in UV light and it increased continuously in moonlight, control and in sunlight. The maximum absorbance peak was observed in sunlight at $550 \mathrm{~nm}$. The range of the AuNPs also results of the intensity of the light. If the intensity of the light is high then the size of the particles will be smaller and the reduction rate will be high.

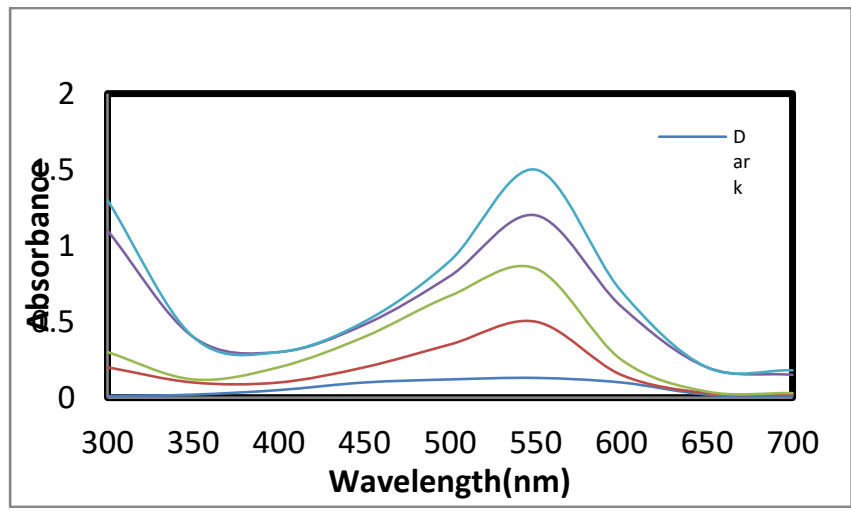

Fig.5 UV-Visible spectra if AuNPs synthesized by Zea Mays (Maize) extract in different light conditions.

\section{E. Effect of Temperature}

Temperature decides the formation of AuNPs. The multiple samples were prepared at different temperature conditions such as $0^{\circ} \mathrm{c}, 5^{\circ} \mathrm{c}, 30^{\circ} \mathrm{c}, 45^{\circ} \mathrm{c}, 75^{\circ} \mathrm{c}$ and $90^{\circ} \mathrm{c}$ and the highest SPR peak recorded at $75^{\circ} \mathrm{C}$ which was shown in figure Fig. 6 and also noticed that SPR peak increased as temperature increased because as temperature increased the nucleation of Gold nanoparticles is also increased. At higher temperature the range of the AuNPs becomes smaller, which indicates through the sharpness of absorbance peak.

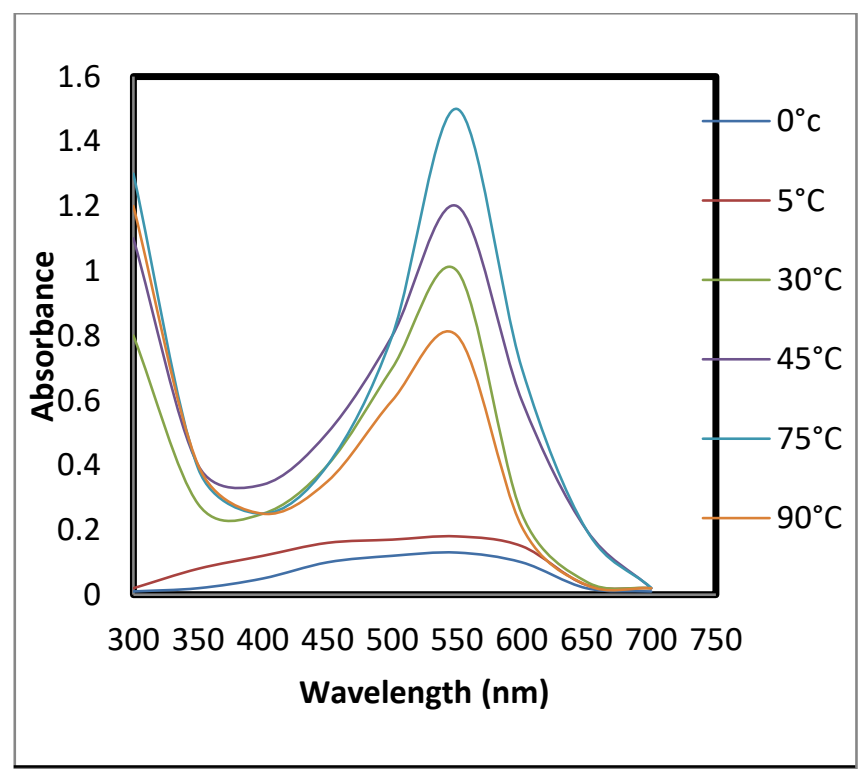

Fig.6 UV-Visible spectra if AuNPs synthesized by Zea Mays (Maize) extract at different temperature Conditions

\section{F. Dynamic Light scattering}

A DLS technique was used to analyze the size distribution of tiny particles within the range of nanometer $2-500 \mathrm{~nm}$ in mixture solution and it depends on the character of light with the gold nanoparticles. Physiochemical properties are very important for the investigation of biological activities of gold nanoparticles through dynamic light scattering [7].among all the techniques which can be used for the measurement of size distribution, DLS is very important method for size. In this method a laser light enters through the suspension and gives the information of the suspended gold nanoparticles. The size analysis by DLS is always greater than the size measured by the Transmission electron microscopy due to the Brownian motion[8].

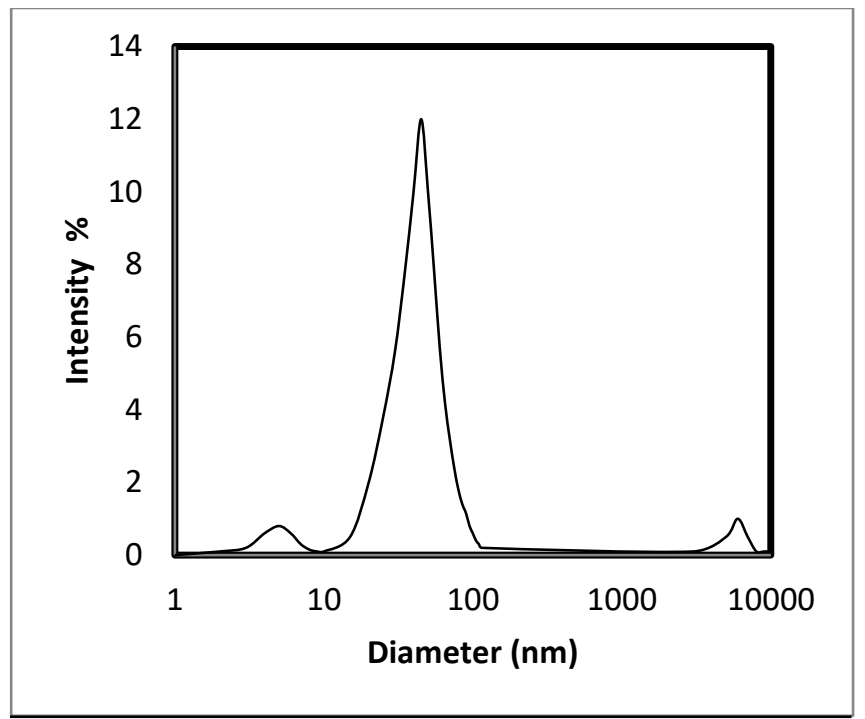

Fig.7 Dynamic Light scattering spectra for the measurement of the size of (AuNPs)

\section{G. TEM Analysis}

The range and shape of the green AuNPs was analyzed through TEM (Fig.7) and results showed that the green AuNPs were in spherical shape and the size range of AuNPs from 6-50 nm. According to the literature the gold nanoparticles were confirmed by TEM was $30 \mathrm{~nm}[8,9]$.

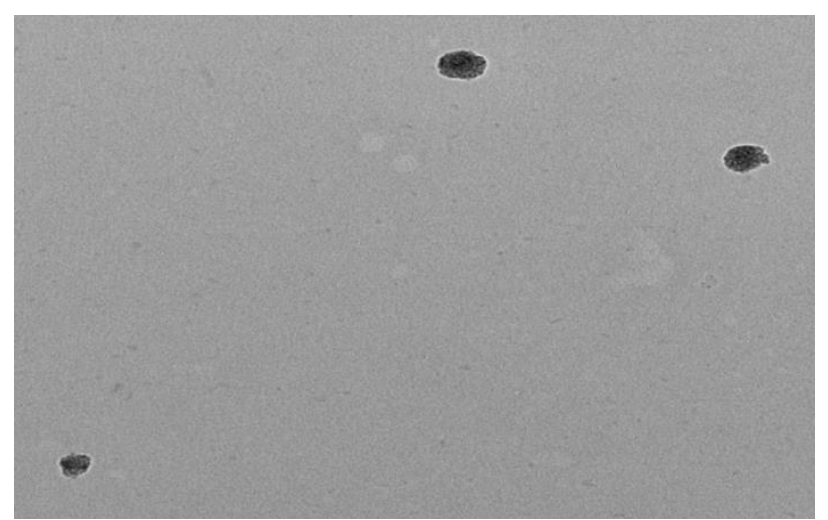

Fig.8 TEM image of AuNPs synthesized from Zea Mays extracts $(50 \mathrm{~nm})$.

Published By: 


\section{Effect of Physical Parameters on Green Synthesis of Gold Nanoparticles using Zea Mays Extract}

\section{CONCLUSION}

After the investigation of various physical parameters like Time, $\mathrm{pH}$, Temperature, Light and Concentration the results showed that these parameters plays an important role for the preparation of green gold nanoparticles. The reaction became stagnant after 90 minutes. The highest absorbance peak was observed between the $\mathrm{pH}=6$ to 7 in sunlight at the concentration of $1 \mathrm{mM}$ solution but as the heat given to the solution the temperature increases at $75^{\circ} \mathrm{C}$ the absorbance peak was maximum. According to the TEM and DLS observation the size range of the green AuNPs is 6-50 nm.

\section{ACKNOWLEDGMENT}

Presented research work was financially supported by the Dean office, faculty of science, SHUATS Prayagraj (ID. No- 13PHPHY202). We thank, Dr. Sanish Thomas, Dr. Mohit James and Dr. Piyush masih for their support and guidance to complete this work.

\section{REFERENCES}

1. Jon R., Singh V., Jayapandian DP., A study on green reducing agents for gold nanoparticles. Advanced materials proceedings, 2017, 2(6), 410-412

2. Muhammad Irfan et al 2017 IOP Conf. Ser.: Mater. Sci. Eng. 204 012002

3. Vanaja, Mahendran \& Gurusamy, Annadurai. (2012). Coleus aromaticus leaf extract mediated synthesis of silver nanoparticles and its bactericidal activity. Applied Nanoscience. 3. 10.1007/s13204012-0121-9.

4. Ankamwar, B., Chaudhary, M. and Sastry, M., Metal-Organic and Nano-Metal Chemistry, (2005)35, 19-26.

5. P. Mohanpuria, N.K. Rana, S.K. Yadav, J. Nanopart. Res. 10 (2008) 507-517.

6. Morel AL, Giraud S, Bialecki A, Moustaoui H, de La Chapelle ML, Spadavecchia J. Green extraction of endemic plants to synthesize gold nanoparticles for theranostic applications. Frontiers in Laboratory Medicine. 2017 Sep 1;1(3):158-71.

7. Siddiqi KS, Husen A. Recent advances in plant-mediated engineered gold nanoparticles and their application in biological system. Journal of Trace Elements in Medicine and Biology. 2017 Mar 1;40:10-23.

8. Sapsford, K.E.; Tyner, K.M.; Dair, B.J.; Deschamps, J.R.; Medintz, I.L. Analyzing nanomaterial bioconjugates: A review of current and emerging purification and characterization techniques. Anal. Chem. 2011, 83, 4453-4488.

9. Tomaszewska, E.; Soliwoda, K.; Kadziola, K.; Celichowski, G.; Cichomski, M.; Szmaja, W.; Grobelny, J.Detection limits of DLS and UV-vis spectroscopy in characterization of polydisperse nanoparticles colloids.J. Nanomater. 2013, 2013, 313081.

10. Jon R, Dasari PR, Singh V and Jayapandian DP: Utilization of Maize extract for the synthesis and characterization of gold nanoparticles at room temperature. Int J Pharm Sci \& Res 2019; 10(5): 2397-02. doi: 10.13040/IJPSR.0975-8232.10(5).2397-02

\section{AUTHORS PROFILE}

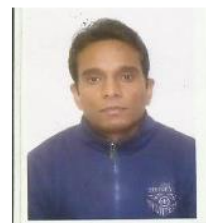

Ravi Jon received B.Sc. (PCM) degree from Bundelkhand University, Uttar Pradesh and M.Sc. physics from Chaudhary Charan Singh University, Meerut Uttar Pradesh India. He btained his M.Tech from Sam Higginbottom Institute of Agriculture Technology and Sciences, Allahabad. Presently Ravi Jon is working as assistant Professor in the Department of Physics, faculty of Sciences, SHUATS, and Prayagraj, INDIA. His research interest is wireless Power Transfer and its applications in biomedical engineering, Nonmaterial, Green Synthesis of Nanoparticles and its Application in biomedical engineering.

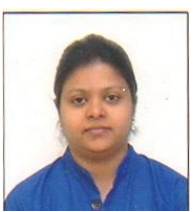

Neha Martin received GNM from Subharat University Merrut, Uttar Pradesh and Post. B.Sc. Nursing from Barakatullaha University Bhopal, Madhya Pradesh. Presently she is working as Nursing Tutor in Christian College of Nursing, SHUATS, Prayagraj, her research focus is infertility in women's,
Hormonal disorder, Cancer and Tumor and other Biological Applications.

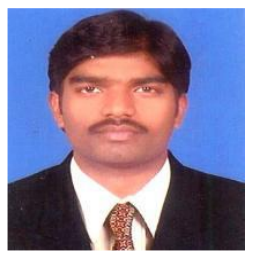

Dr. Prabhakara Rao Dasari received B.Sc. PCM degree from Nagaarjuna University and M.Sc. physics from Andhra University, India. He obtained his P.hD. from Sam Higginbottom Institute of Agriculture Technology and Sciences, Allahabad. Presently Dr. Dasari is working as Teaching Assistant in the Department of Chemistry, faculty of Sciences, SHUATS, and Prayagraj, INDIA. His research interest is Nonmaterial, Green Synthesis of Nanoparticles and its Applications in cancer.

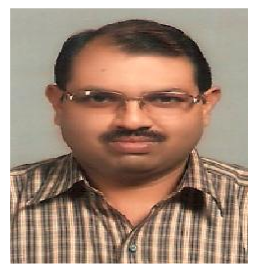

Dr. Ajit Paul received B.Sc. degree from Kanpur University, M.Sc. and M.Phil from Agra University Agra, Uttar Pradesh and D.Phil from Allahabad University. Presently Dr. Paul is working as Head Department of mathematics and Statistics, Head Department of Physics, Dean Faculty of Science and Chairman Examination and Entrance, SHUATS, Prayagraj INDIA. His research focus is Group Theory and Operation Research. new techniques in mathematics and Statistics,

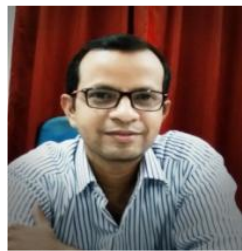

Dr. Vipul Singh received B.Sc. PCM degree from Bundelkhand University and M.Sc. physics from Bundelkhand University, India. He obtained his P.hD. from Sam Higginbottom Institute of Agriculture Technology and Sciences, Allahabad. Presently Dr. Singh is working as Assistant Professor in the Department of Physics, faculty of Sciences, SHUATS, and Prayagraj, INDIA. His research interest is Nonmaterial, Superconductivity and cryptography 